\title{
Medical simulation center as a model for testing mHealth concepts in prehospital emergency medicine
}

\author{
Dr. med. Bibiana Metelmann, M.D. \\ Klinik fuer Anaesthesiologie, Universitaetsmedizin \\ Greifswald, Ferdinand Sauerbruch Straße 17475 \\ Greifswald, Germany \\ Email: bibiana.metelmann@uni-greifswald.de
}

\author{
Dr. med. Camilla Metelmann, M.D. \\ Klinik fuer Anaesthesiologie, Universitaetsmedizin \\ Greifswald, Ferdinand Sauerbruch Straße 17475 \\ Greifswald, Germany \\ Email: camilla.metelmann@uni-greifswald.de
}

\begin{abstract}
Newly developed mHealth tools need to be tested in standardized conditions without possible patient harm before implementation. One possible approach to secure these two conditions is to analyze the mHealth tool in a medical simulation center. Medical simulation centers create realistic routine or emergency scenarios with the aid of computeroperated mannequins. Medical simulation is widely established, especially in emergency medicine, because it combines theoretical knowledge and practical skills. To evaluate a mHealth concept in the field of prehospital emergency medicine in a medical simulation center, distinctive scenarios should be used. The mHealth concept in this study was a mobile, high definition, real-time video connection between the emergency site and a remote medical expert. Since all participants in this study confirmed that the chosen scenarios were realistic and relevant, a medical simulation center appears to be a suitable model for testing mHealth concepts in prehospital emergency medicine.
\end{abstract}

\section{INTRODUCTION}

$\mathrm{N}^{\mathrm{s}}$ EWLY developed mHealth tools need to be tested in standardized conditions without possible patient harm before implementation. One possible approach to secure these two conditions is to analyze the mHealth tool in a medical simulation center.

As AMMENWERTH and co-workers have explained [1], there are three ways of testing a new health information technology. The first way is to evaluate it in a laboratory, but the results are limited by a low external validity. The second way is a field evaluation test, but for this, both software and hardware have to be sufficiently mature to not possibly harm any person. So the solution is often the third way: a study in a medical simulation center, which combines good internal and external validity [1]. Usability studies in medical simulation centers are ideal for objective, structured analysis of new technical devices [2].

The present article has been structured in the context of the LiveCity ("Live Video-to-Video Supporting Interactive City Infrastructure") European Research Project and has been supported by the Commission of the European Communities - DG CONNECT (FP7-ICT-PSP, Grant Agreement No.297291).
Simulations in general provide the facility to evaluate complex systems and the interaction of the different variables [3], [4]. MHealth concepts in emergency scenarios can be tested in computer generated simulation or in medical simulation centers. It could be shown that the former, for instance in the form of virtual reality, is a successful way of analyzing for instance fire emergencies [5]. This paper aims to analyze how the latter can be used to test mHealth concepts. In medical simulation centers (study) participants encounter realistic routine or emergency scenarios, which are created with the aid of computer-operated mannequins [6]. These scenarios are based on predefined, structured protocols, but are adapted dynamically, depending on the action of the participants. Thus, the participants see and feel the consequences of their individual actions [7]. Because medical simulation combines theoretical knowledge and practical skills, it is widely established, especially in emergency medicine [8], [9], [10]. It is frequently and successfully used in training at all stages of medical education and in research [11], [12]. It can be used for both individual settings and group settings and offers the opportunity to standardize while minimizing negative consequences of potential errors [9], [13].

Simulation studies offer the opportunity to conduct experimental cross-over trials with high internal validity. The external validity depends on how realistic the simulated scenarios are. The perception of how realistic a scenario in a simulation centre is, is influenced by three different aspects: the equipment fidelity, the environment fidelity and the psychological fidelity [14]. The equipment fidelity is characterized by the used hardware and software. The environment fidelity is mostly created by the appropriate surrounding for every scenario. Psychological fidelity is the ability of the individual participant to immerse into the simulated situation. Psychological fidelity can be increased by enhancing equipment and environment fidelity [15].

To evaluate a mHealth concept in the field of prehospital emergency medicine in a medical simulation center, distinctive scenarios should be used. Hence, it is important to generate scenarios of emergencies, which occur often and in 
which an early start of the right therapy has a huge impact on morbidity and mortality. Three paramount examples are stroke, myocardial infarction and trauma. These emergencies belong to the "First Hour Quintet", termed by the European Resuscitation Council. It describes five emergencies, which are life-threatening diseases, which require fast treatment [16], [17]. Stroke, myocardial infarction and trauma are also among the main causes of death in Europe [18]. Worldwide, they belonged to the group of top 10 leading causes of death in 2004 and prognosis for 2030 predicts them to be within the top 5 leading causes of death worldwide [19]. Thus, there are many approaches to improve the therapy of these emergencies; among them the application of mHealth. It could be shown, that mHealth for stroke in prehospital emergency medicine is feasible and beneficial [20].

To reflect the broad spectrum of emergencies, it is also important to include emergencies, which are especially challenging. Examples for those emergencies could be rare diseases and difficulties during pregnancy. The treatment of rare diseases often lacks standard operating procedures. Additionally, the emergency personnel might not have encountered a similar situation before, which increases the stress level. The complexity of difficulties during pregnancy is caused by the fact that the unborn child has to be considered, too. For instance, there are only a limited number of pharmaceuticals, for which it could be proven, that they can be administered during pregnancy without teratogenic or negative long-term effects for the unborn child [21]. Additionally, pregnancy changes many physiological parameters in women, which have to be kept in mind.

\section{II.MATERIAL AND METHODS}

To test the hypothesis, that medical simulation centers are ideal for testing mHealth concepts in prehospital emergency medicine, ten typical emergency scenarios were prepared from five different categories: "Stroke", "Myocardial infarction", "Trauma", "Rare diseases" and "Difficulties during pregnancy". All scenarios were structured to be handled according to the worldwide used "ABCDE"approach to rapidly evaluate the emergency situation: " $A$ " for airway, "B" for breathing, "C" for circulation, "D" for disability, "E" for exposure. Relevant details of the case have been included to be recognised by "SAMPLE"-history: "S" for symptoms, "A" for allergies, " $\mathrm{M}$ " for medication, "P" for past medical history, "L" for last oral intake and "E" for events leading to the illness/injury [22], [23].

The mHealth concept in this study was a mobile, high definition, real-time video connection between the emergency site and a remote medical expert. For this purpose a camera called LiveCity camera was used, which was developed in the European Union funded research project LiveCity [24], [25], [26].
According to usual guidelines in German emergency medicine two paramedics worked together as a team. Together they handled ten scenarios, five of them with a remote medical expert and five of them without. The sequence of the case scenarios and the assignment to the two cross-over categories was randomized.

When paramedics are alerted by the emergency dispatcher, they are provided with information about the location of the emergency, age and gender of the patient and the operation key word. The operation key word is based on the callers description of the emergency and indicates the kind of emergency [27], [28]. For all 10 scenarios in this study operation key words were developed. In general, every scenario followed this pattern:

The paramedics were presented with the operation key words and age and gender of the patient. After that, they entered the simulation room, where the mannequin was postured with additional props, to illustrate the specific emergency scenario. The paramedics then started to ask the mannequin questions regarding the emergency, took the medical history, measured the vital signs and examined the patient. According to the predefined case description, which was developed specifically for every scenario, questions were answered and the vital signs and findings in the physical examination shown. They were dynamically adjusted according to the actions of the paramedics. In the simulation cases with a remote medical expert, the paramedics could decide at which point during the simulation they wanted to start the video consultation. Depending on features of the emergency case (for instance the severeness and the urgency to start the treatment) and on traits of the paramedic (like level of experience and wish for reassurance) the consultation could start either right after hearing the operation key word or after finishing the diagnostics and initial treatment just for confirmation or at any given moment between that, as would be the case after the implementation of this mHealth system. All the scenarios ended, when the paramedics decided to start the transport to the hospital. That endpoint was chosen, because before the beginning of the transport, all major decisions regarding diagnostics and treatment have to be made. If the paramedics did not start transport within 27 minutes, the scenarios were terminated. This time limit was set, because in Germany in $95 \%$ the emergency doctor reaches the emergency site within 26.6 minutes [29]. Thus, in the majority of cases there would be an emergency doctor at the emergency site after 27 minutes to take over from the remote medical expert.

For the simulation in this study, the equipment of the paramedics contained all medical devices, that are statutory for an ambulance car in Germany according to DIN EN 1789 Typ C [30], [31]. These are, for instance, monitor of medical parameters (including body temperature, blood sugar level and 12-lead-ECG) and defibrillator, ventilator machine, medical suction machine, stiff neck and medical bag with 
drugs, dressing and devices to secure the airway and blood circulation.

The study was performed in the fully equipped high fidelity medical simulation center of the Department of Anaesthesiology at Greifswald University Medicine. To assess the outcome in practical, technical and psychological aspects, paramedics and doctors were interviewed by use of semi-structured questionnaires.

\section{RESULTS}

A total of 10 emergency doctors and 21 paramedics took part. Among the many aspects assessed by questionnaires in the LiveCity project, three key findings for this study will be presented. Table I shows how doctors and paramedics rated the statement "The scenarios were realistic." Table II shows how doctors and paramedics rated the statement "The scenarios were relevant." Table III shows how doctors and paramedics rated the statement "I took the simulation work seriously."

Table I: "The scenarios were realistic."

\begin{tabular}{|l|l|l|l|l|}
\hline & Agree & $\begin{array}{l}\text { Partly } \\
\text { agree }\end{array}$ & $\begin{array}{l}\text { Partly } \\
\text { disagree }\end{array}$ & Disagree \\
\hline Doctors (10) & 4 & 5 & 1 & 0 \\
\hline Paramedics (21) & 9 & 11 & 1 & 0 \\
\hline
\end{tabular}

Table II: "The scenarios were relevant."

\begin{tabular}{|l|l|l|l|l|}
\hline & Agree & $\begin{array}{l}\text { Partly } \\
\text { agree }\end{array}$ & $\begin{array}{l}\text { Partly } \\
\text { disagree }\end{array}$ & Disagree \\
\hline Doctors (10) & 7 & 3 & 0 & 0 \\
\hline Paramedics (21) & 14 & 7 & 0 & 0 \\
\hline
\end{tabular}

Table III: "I took the simulation work seriously."

\begin{tabular}{|l|l|l|l|l|}
\hline & Agree & $\begin{array}{l}\text { Partly } \\
\text { agree }\end{array}$ & $\begin{array}{l}\text { Partly } \\
\text { disagree }\end{array}$ & Disagree \\
\hline Doctors (10) & 6 & 4 & 0 & 0 \\
\hline Paramedics (21) & 18 & 3 & 0 & 0 \\
\hline
\end{tabular}

\section{DISCUSSION}

In this study, the majority of emergency doctors and paramedics confirmed that the simulation of the scenarios was realistic. They also acknowledged that the chosen scenarios were relevant examples of emergency situations.
All paramedics and emergency doctors agreed or partly agreed that they took the simulation work seriously.

Great emphasis was put on high verifiability, fidelity and validity, which are three of the most important concepts of evaluating the quality of simulation [32]. These three concepts are interconnected. To achieve high verifiability, all 10 developed scenarios were tested and adapted beforehand. As mentioned above, the fidelity can be divided into equipment fidelity, environment fidelity and psychological fidelity. To increase the equipment fidelity in this study, the Laerdal mannequin Resusci Anne® (Laerdal Medical $\mathrm{GmbH}$, Puchheim, Germany) was used and the vital signs were dynamically simulated with the monitor iSimulate ALSi ${ }^{\circledR}$ (Skillqube GmbH, Wiesloch, Germany). The Laerdal Resusci Anne is globally used in education and research [33], [34], [35]. To enhance environment fidelity, every scenario had different characteristic accessories, e.g. in one case of simulated heart attack, a patient was watching sports sitting on a sofa with a football flag while eating potato crisps. Psychological fidelity is the ability of the individual participant to immerse into the simulated situation. Because the psychological fidelity depends on equipment and environment fidelity, huge emphasis has to be on increasing both of the latter. In the concept, that the behaviour in the simulated scenario mirrors the behaviour in a real case, high authenticity is essential [36]. In this study all participants took their work very seriously during the simulation, and the majority rated the simulated scenarios as realistic. Thus, the possibility of the participants behaving in the study environment similar to their normal behaviour is very high. This implies a good external validity. Furthermore, all emergency doctors and paramedics partly agreed or agreed that the chosen scenarios were relevant. This is also an indicator for a good external validity.

\section{V.CONCLUSION}

Since all paramedics and emergency doctors confirmed that the chosen scenarios were realistic and relevant, a medical simulation center appears to be a suitable model for testing mHealth concepts in prehospital emergency medicine. It offers the opportunity to evaluate mHealth concept without potential patient harm.

\section{ACKNOWLEDGMENT}

The authors would like to thank Professor Michael Wendt, Professor Konrad Meissner and Professor Klaus Hahnenkamp for their continuous support.

\section{REFERENCES}

[1] Ammenwerth, E., Hackl, W.O., Binzer, K., Christoffersen, T.E., Jensen, S., Lawton, K., Skjoet, P., and Nohr, C.: 'Simulation studies for the 
evaluation of health information technologies: experiences and results', The HIM journal, 2012, 41, (2), pp. 14-21,

[2] Landman, A. B., Redden, L., Neri, P., Poole, S., Horsky, J., Raja, A. S., Pozner, C. N., Schiff, G., and Poon, E.G.: 'Using a medical simulation center as an electronic health record usability laboratory', Journal of the American Medical Informatics Association : JAMIA, 2014, 21, (3), pp. 558-563, doi:10.1136/amiajnl-2013-002233

[3] Cossentino, M., Lodato, C., Ribino, P., and Seidita, V.: 'A heuristic for Problem Formalization in Agent Based Simulation studies', in Editor $(\text { Ed. })^{\wedge}$ (Eds.): 'Book A heuristic for Problem Formalization in Agent Based Simulation studies' (2015, edn.), pp. 1733-1743, doi: $10.15439 / 2015 \mathrm{~F} 287$

[4] Preisler, T., Dethlefs, T., and Renz, W.: 'Simulation as a service: A design approach for large-scale energy network simulations', in Editor (Ed. $)^{\wedge}$ (Eds.): 'Book Simulation as a service: A design approach for large-scale energy network simulations' (2015, edn.), pp. 1765-1772, doi:10.15439/2015F116

[5] Kinateder, M., Ronchi, E., Nilsson, D., Kobes, M., M, M., x00Fc, ller, Pauli, P., A, M., x00Fc, and hlberger: 'Virtual reality for fire evacuation research', in Editor (Ed.)^(Eds.): 'Book Virtual reality for fire evacuation research' (2014, edn.), pp. 313-321, doi:10.15439/2014F94

[6] Johannsson, H., Ayida, G., and Sadler, C.: 'Faking it? Simulation in the training of obstetricians and gynaecologists', Current opinion in obstetrics \& gynecology, 2005, 17, (6), pp. 557-561,

[7] Gredler, M. E.: 'Games and simulations and their relationships to learning', Handbook of research on educational communications and technology, 2004, 2, pp. 571-581,

[8] Gaba, D.M.: 'The future vision of simulation in healthcare', Simulation in healthcare : journal of the Society for Simulation in Healthcare, 2007, 2, (2), pp. 126-135, doi:10.1097/01.sih.0000258411.38212.32

[9] Kyle, R., and Murray, W. B.: 'Clinical Simulation' (Elsevier Science, 2010. 2010), [10] Lestander, Ö., Lehto, N., and Engström, A.: 'Nursing students' perceptions of learning after high fidelity simulation: Effects of a Three-step Post-simulation Reflection Model', Nurse Education Today, 2016, 40, pp. 219-224, doi:http://dx.doi.org/10.1016/j.nedt.2016.03.011

[11] Melbye, S., Hotvedt, M., and Bolle, S.: 'Mobile videoconferencing for enhanced emergency medical communication - a shot in the dark or a walk in the park? -- A simulation study', Scandinavian journal of trauma, resuscitation and emergency medicine, 2014, 22, (1), pp. 35,

[12] Cannon-Diehl, M. R.: 'Simulation in healthcare and nursing: state of the science', Critical care nursing quarterly, 2009, 32, (2), pp. 128-136, doi:10.1097/CNQ.0b013e3181a27e0f

[13] Muller-Juge, V., Cullati, S., Blondon, K.S., Hudelson, P., Maitre, F., Vu, N.V., Savoldelli, G.L., and Nendaz, M. R.: 'Interprofessional collaboration between residents and nurses in general internal medicine: a qualitative study on behaviours enhancing teamwork quality', PloS one, 2014, 9, (4), pp. e96160, doi:10.1371/journal.pone. 0096160

[14] Fritz, P. Z., Gray, T., and Flanagan, B.: 'Review of mannequin-based high-fidelity simulation in emergency medicine', Emergency Medicine Australasia, 2008, 20, (1), pp. 1-9, doi:10.1111/j.17426723.2007.01022.x

[15] Bauman, E. B.: 'Game-based Teaching and Simulation in Nursing and Healthcare' (Springer Publishing Company, 2013. 2013),

[16] Krafft, T., Garcia Castrillo-Riesgo, L., Edwards, S., Fischer, M., Overton, J., Robertson-Steel, I., and Konig, A.: 'European Emergency Data Project (EED Project): EMS data-based health surveillance system', European journal of public health, 2003, 13, (3 Suppl), pp. $85-90$,

[17] Nilsen, J. E.: 'Improving quality of care in the Emergency Medical Communication Centres (EMCC) '. Proc. Konferanse for medisinsk nødmeldetjeneste 7. - 8.nov. 2012, Sola, Norway, 8.11.2012 2012

[18] Fischer, M.: 'Factors influencing outcome after prehospital emergencies - a european perspective'. Proc. EUROANESTHESIA 2007, München, Deutschland, 9.6.2007 2007.

[19] WHO: 'Injuries and violence: the facts', in Editor (Ed.)^(Eds.): 'Book Injuries and violence: the facts' (2010, edn.).

[20] Hubert, G., Müller-Barna, P., and Audebert, H.: 'Recent advances in TeleStroke: a systematic review on applications in prehospital management and Stroke Unit treatment or TeleStroke networking in developing countries', International Journal of Stroke, 2014, 9, (8), pp. 968-973, doi:10.1111/ijs.12394

[21] Grzeskowiak, L. E., Gilbert, A. L., and Morrison, J. L.: 'Methodological challenges in using routinely collected health data to investigate long-term effects of medication use during pregnancy', Therapeutic advances in drug safety, 2013, 4, (1), pp. 27-37, doi:10.1177/2042098612470389

[22] Thim, T., Krarup, N. H., Grove, E. L., Rohde, C. V., and Lofgren, B.: 'Initial assessment and treatment with the Airway, Breathing, Circulation, Disability, Exposure (ABCDE) approach', International journal of general medicine, 2012, 5, pp. 117-121, doi:10.2147/ijgm.s28478

[23] Henry, M. C., Stapleton, E. R., and Edgerly, D.: 'EMT Prehospital Care' (Mosby JEMS/Elsevier, 2011. 2011)

24] Metelmann, B. and Metelmann, C.: 'M-Health in Prehospital Emergency Medicine: Experiences from the EU funded Project LiveCity', in Anastasius, M. (Ed.): 'M-Health Innovations for PatientCentered Care' (IGI Global, 2016), pp. 197-212, doi:10.4018/978-14666-9861-1.ch010

[25] Goncalves, J., Cordeiro, L., Batista, P., and Monteiro, E.: 'LiveCity: A Secure Live Video-to-Video Interactive City Infrastructure', in Iliadis, L., Maglogiannis, I., Papadopoulos, H., Karatzas, K., and Sioutas, S. (Eds.): 'Artificial Intelligence Applications and Innovations' (Springer Berlin Heidelberg, 2012), pp. 260-267, doi:10.1007/978-3-642-33412227

[26] Palma, D., Goncalves, J., Cordeiro, L., Simoes, P., Monteiro, E., Magdalinos, P., and Chochliouros, I.: 'Tutamen: An Integrated Personal Mobile and Adaptable Video Platform for Health and Protection', in Papadopoulos, H., Andreou, A., Iliadis, L., and Maglogiannis, I. (Eds.): 'Artificial Intelligence Applications and Innovations' (Springer Berlin Heidelberg, 2013), pp. 442-451, doi:10.1007/978-3-642-41142-7_45

[27] Ellinger, K.: 'Kursbuch ' Notfallmedizin: orientiert am bundeseinheitlichen Curriculum Zusatzbezeichnung Notfallmedizin' (Dt. Ärzte-Verlag, 2011. 2011).

[28] Wölfl, C.G., and Matthes, G.: 'Unfallrettung: Einsatztaktik, Technik und Rettungsmittel ; mit 32 Tabellen' (Schattauer, 2010. 2010).

[29] Schmiedel, R., and Behrendt, H.: 'Leistungen des Rettungsdienstes 2008/09', in Editor (Ed.) $)^{\wedge}$ (Eds.): 'Book Leistungen des Rettungsdienstes 2008/09' (2011, edn.).

[30] Kemper, H.: 'Fahrzeugkunde: Arten und Ausführungen der genormten Feuerwehrfahrzeuge' (Ecomed Sicherheit, 2010. 2010).

[31] Kühn, C.: 'Patienten- und Personenbeförderung: Zulassungs-, betriebsund sicherheitstechnische Begutachtung aktueller Fahrzeugumbauten ; Gutachten über die Zulassung und den Betrieb von sogenannten Multifunktionsfahrzeugen (Liegetaxi, Sondermietwagen, Tragestuhlwagen, Selbstfahrermietliegewagen, Funkmietliegewagen, Liegendtransportwagen)' (Hüthig Jehle Rehm, 2008. 2008).

[32] Feinstein, A.H., and Cannon, H.M.: 'Fidelity, verifiability, and validity of simulation: Constructs for evaluation', Developments in Business Simulation and Experiential Learning, 2001, 28.

[33] Yasuda, Y., Kato, Y., Sugimoto, K., Tanaka, S., Tsunoda, N., Kumagawa, D., Toyokuni, Y., Kubota, K., and Inaba, H.: 'Muscles used for chest compression under static and transportation conditions', Prehospital emergency care : official journal of the National Association of EMS Physicians and the National Association of State EMS Directors, 2013, 17, (2), pp. 162-169, doi:10.3109/10903127.2012.749964

[34] Monsieurs, K.G., De Regge, M., Schelfout, S., D'Hondt, F., Mpotos, N., Valcke, M., and Calle, P.A.: 'Efficacy of a self-learning station for basic life support refresher training in a hospital: a randomized controlled trial', European journal of emergency medicine : official journal of the European Society for Emergency Medicine, 2012, 19, (4), pp. 214-219, doi:10.1097/MEJ.0b013e32834af5bf

[35] Abelairas-Gomez, C., Rodriguez-Nunez, A., Casillas-Cabana, M., Romo-Perez, V., and Barcala-Furelos, R.: 'Schoolchildren as life savers: At what age do they become strong enough?', Resuscitation, 2014, 85, (6), pp. 814-819, doi:10.1016/j.resuscitation.2014.03.001

[36] Cumin, D., Weller, J.M., Henderson, K., and Merry, A.F.: 'Standards for simulation in anaesthesia: creating confidence in the tools', British journal of anaesthesia, 2010, 105, (1), pp. 45-51, doi:10.1093/bja/aeq095 